\title{
Correction to: The Subjective Well-Being of Chilean Children Living in Conditions of High Social Vulnerability
}

\author{
Loreto Ditzel ${ }^{1,2} \mathbb{D} \cdot$ Ferran Casas $^{3,4} \mathbb{D}$. Javier Torres-Vallejos ${ }^{4} \mathbb{D}$. \\ Alejandra Villarroel ${ }^{1}$ (D)
}

Published online: 3 December 2021

(c) The International Society for Quality-of-Life Studies (ISQOLS) and Springer Nature B.V. 2021

\section{Correction to: Applied Research in Quality of Life https://doi.org/10.1007/s11482-021-09979-7}

The original version of the article unfortunately contained an error.

The order of the first author's name is changed. The correct order of the first author's name is shown above.

Publisher's Note Springer Nature remains neutral with regard to jurisdictional claims in published maps and institutional affiliations.

The original article can be found online at https://doi.org/10.1007/s11482-021-09979-7.

Loreto Ditzel

anaditzel@udd.cl

Ferran Casas

ferran.casas@udg.edu

Javier Torres-Vallejos

Javier.torres@unab.cl

Alejandra Villarroel

a.villarroel@udd.cl

1 Faculty of Psychology, Universidad del Desarrollo, Av. Plaza 680Las Condes, Santiago, Chile

2 University of Girona, Girona, Spain

3 Research Institute on Quality of Life, University of Girona, Girona, Spain

4 Faculty of Education and Social Sciences, Universidad Andres Bello, Santiago, Chile 